\title{
Additional detail in aggregate integrated land-use models via simulating developer pro forma thinking
}

\author{
Jerry Johnson \\ Johnson Economics \\ jwj@johnsoneconomics.com
}

\author{
Maribeth Todd \\ Oregon Metro \\ maribeth.todd@oregonmetro.gov
}

\author{
Jeff Frkonja \\ Oregon Metro \\ jeff.frkonja@oregonmetro.gov \\ Dennis Yee \\ Oregon Metro \\ dennis.yee@oregonmetro.gov
}

\begin{abstract}
This paper describes an enhancement to MetroScope, the land-use model component of an integrated model suite used to answer current- and next-generation policy questions facing Oregon Metro (the Portland regional planning organization) and other public agencies. The enhancement is designed to simulate more-detailed housing developer decision processes within an overall aggregate spatial equilibrium model (SEM) framework via a pro forma paradigm. The paper enumerates the policy questions that motivated the enhancement, discusses the integrated model framework, briefly reviews levels of detail available in existing models as context, and frames potential future research directions for additional decision process detail that would be helpful in the consumer modules of the model and potentially other SEMs currently in use.
\end{abstract}

\section{Article history:}

Received: March 31, 2017

Received in revised form: October 19, 2017

Accepted: February 6, 2018

Available online: June 21, 2018

\section{Introduction}

Metro - the Portland Oregon area's regional government-performs land use planning under Oregon law including defining the region's Urban Growth Boundary (UGB) in response to an analyticallydemonstrated "need" for land capacity (State of Oregon, revised statutes 197.296). The authors of this paper provide Oregon Metro decision-makers and stakeholders with forecasts from integrated models to support that and other decisions. Our thesis - in answer to the "more detail or less detail in integrated models?" question posed by this special edition's editors—is that we need more details in our integrated models to better serve our clients. This article describes available levels of detail in Metro's and others' current applied models and frames emerging policy questions facing public sector decision-makers.

Copyright 2018 Jerry Johnson, Jeff Frkonja, Maribeth Todd \& Dennis Yee http://dx.doi.org/10.5198/jtlu.2018.1189

ISSN: 1938-7849 | Licensed under the Creative Commons Attribution - Noncommercial License 4.0

The Journal of Transport and Land Use is the official journal of the World Society for Transport and Land Use (WSTLUR) and is published and sponsored by the University of Minnesota Center for Transportation Studies. 
The paper proceeds to describe means of incorporating additional detail in housing supplier decision simulation in an aggregate model framework to help answer those questions, specifically by simulating housing developers' pro forma decision processes. We conclude by briefly remarking how this approach may help the general forecasting community and with suggestions for possible future research directions on consumer decision-making.

Practitioners need many specialized models to treat the different spheres of human activity affected by public decisions in the real world. For example, macro-economic conditions influence the number of travelers moving about a region on any given day while the ease of moving people and goods effects regions' economic viability. The field has many examples of models simulating these diverse activities that are methodologically integrated regardless of their formal "coupling" in software code (Anas \& Liu, 2007; Pendyala et al., 2014; Wegener, 2012; Zhang \& Kockelman, 2016). Figure 1 shows such a "model chain" with feedback loops implemented in current practice in purple lines (see for example Pendyala et. al., 2014; Puget Sound Regional Council, 2015) and potential, to-be-developed feedback loops (red lines). The "local impacts" element of the workflow represents any number of operations that estimate direct effects on people including air and water quality, noise, health impacts, transport system user benefits, and so on.

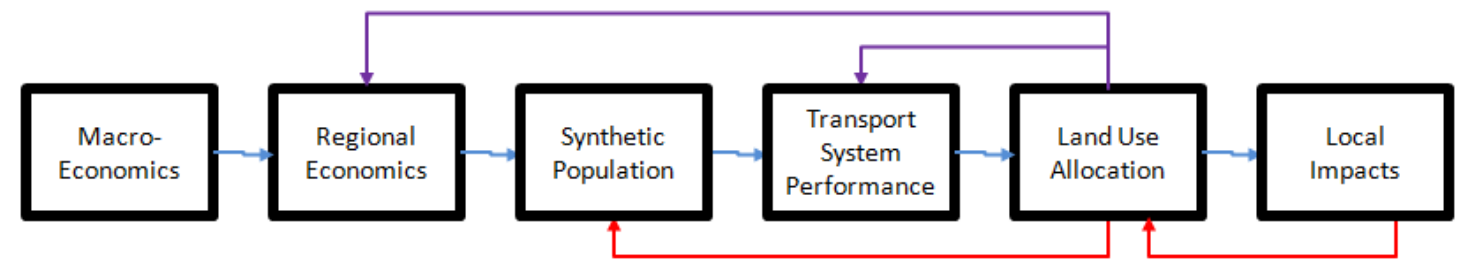

Figure 1: Model integration conceptual architecture

The opportunities to estimate detail in integrated models occur across multiple dimensions: temporal; geographic; the granularity of agent representation (e.g., individuals, firms, households); the complexity of the treatment of various agents' business, household, or personal decision processes; and the number of endogenous variables affecting agents' decisions (income, household size, etc.).

\section{Integrated model details available today}

Academic and applied research to date has produced high levels of detail in many of the individual models in the chain. Table 1 summarizes these achievements and shows that in current practice models have reached the greatest useful atomic detail in several areas: consumer agent representation, geographic unit of analysis, and temporal scale (Felsenstein, Axhausen, \& Waddell, 2010; Pendyala et al., 2014; Waddell, 2013). Key areas remaining open to additional detail are the behavioral nuances of suppliers' decisionmaking, additional behavioral nuances of households regarding their long-term location choices, and the simulation of market interactions in the context of agents' individual choices. Discussions between model creators in the literature (Anas, 2013; Zhang \& Kockelman, 2016) point out that in the very broadest sense agent-based models (we use the acronym ABM for transport models and ALUM for land use in this article) focus on achieving greater agent detail while spatial equilibrium models (SEMs) have focused on price-driven market interaction details in search of a market-clearing equilibrium solution. These two broad model practices may start to converge as ALUMs incorporate market-clearing features (Wang, 2013). 
Table 1: Current models' detail levels

\begin{tabular}{|c|c|c|}
\hline Model Element & Detail in Proven Models & Proven Models \\
\hline $\begin{array}{l}\text { Consumer Representation (Land } \\
\text { Use) }\end{array}$ & Household & $\begin{array}{l}\text { Agent-based Land Use Model } \\
\text { (ALUM) } \\
\text { Activity-Based travel Model (ABM) }\end{array}$ \\
\hline $\begin{array}{l}\text { Consumer Representation } \\
\text { (Transport) }\end{array}$ & Person & ABM \\
\hline Land Use Geography & Parcel (Tax Lot) & ALUM, ABM \\
\hline Transport Geography & $\begin{array}{l}\text { "All Streets" and off-street "Active } \\
\text { Transport" links }\end{array}$ & ABM \\
\hline Temporal scale & $\begin{array}{l}\text { Fifteen- to Thirty-minute time slices } \\
\text { for much of a typical weekday }\end{array}$ & $\begin{array}{l}\text { ABM integrated with Dynamic } \\
\text { Traffic Assignment (DTA) }\end{array}$ \\
\hline $\begin{array}{l}\text { Consumer Decision-Making } \\
\text { Behavior (Transportation) }\end{array}$ & $\begin{array}{l}\text { Individual traveler and intra- } \\
\text { household choices }\end{array}$ & ABM \\
\hline $\begin{array}{l}\text { Consumer Decision-Making } \\
\text { Behavior (Land Use) }\end{array}$ & $\begin{array}{l}\text { Some detail } \\
\text { (for households via income, } \\
\text { household size, and age of head-of- } \\
\text { household) }\end{array}$ & ALUM \\
\hline $\begin{array}{l}\text { Property Supplier Representation } \\
\text { (Land Use) }\end{array}$ & Relatively little & $\begin{array}{l}\text { Agent-based freight models } \\
\text { (ABFMs) create synthetic firm } \\
\text { populations but practical land use } \\
\text { allocation models have not yet } \\
\text { microsimulated firms }\end{array}$ \\
\hline $\begin{array}{l}\text { Property Supplier Decision-Making } \\
\text { (Land Use) }\end{array}$ & Relatively little & $\begin{array}{l}\text { ALUMs have established a } \\
\text { framework but lack of data has } \\
\text { made supplier simulation } \\
\text { challenging }\end{array}$ \\
\hline Market Interactions & $\begin{array}{l}\text { Price response at aggregated } \\
\text { market segments and aggregate } \\
\text { geographies }\end{array}$ & Spatial Equilibrium Models (SEMs) \\
\hline
\end{tabular}

\section{Topical policy questions for urban planners and decision-makers}

Our thesis that we need more model detail in supplier decision-making simulation is driven by both the evolution of regional land markets and by the policy questions public decision-makers are now asking. Metro and other regions have urbanized rapidly over the past decade leading to development that utilizes already-built land by adding housing units while preserving existing ones (infill) or replacing existing structures with new construction (re-development). For example, in the period 2007 to 2012 about $58 \%$ of housing production within Metro's UGB occurred through infill, and more importantly, re-development (Oregon Metro, 2014). Other cities like Seattle are debating whether re-development is producing enough new units (Phelps-Goodman, 2016). These examples highlight the fact that many regions' housing markets now depend as much or more on re-developing already-built lands than on utilizing greenfields. Re-development is more expensive and difficult to implement than greenfield development for several reasons, the most obvious of which is that developers must add atop construction and property acquisition costs the expense of demolishing some existing structure. Given these factors Metro's decision-makers ask questions such as: what factors promote (or hinder) re-development? What specifically could the public sector do to promote re-development? We believe that Metro's and others' models would be more effective at answering such questions in densifying urban areas through use of additional endogenous variables that provide more-detailed treatments of supplier decision-making. The main part of this paper describes a model technique we developed for doing so.

In addition to re-development topics the Portland area and other regions have made significant 
investments in active transportation (bicycle and pedestrian) infrastructure, transit, and land development supportive of those modes. Our transport models are sensitive to these mode choices but other researchers have made the case (Mokhtarian \& van Herick, 2016) that public goods in the built environment also influence households' choice of where to live. Our policy-makers would like to quantify the potential impacts of such investments in both transport and land use policy arenas. In other words, what is the return on public investment in neighborhood-scale amenities? In the "future research" section of this paper we conceptualize a potential enhancement to our models in this realm.

\section{$4 \quad$ Existing metro models}

Metro forecasts future land use using three econometric models (the Regional Economic Model, Regional Travel Demand Model, and MetroScope) plus a sub-allocation process called Mapback. As Figure 2 shows, Metro integrates these tools by transferring data outputs from one to the other. Exogenouslyproduced data such as future transportation system supply characteristics, national economic performance, and existing land use feed this model chain. As the figure shows the lynchpin of the process from a land use perspective is the MetroScope land use allocation model. Staff input agents to MetroScope in the form of a distribution of synthetic households by household size group $(\mathrm{H})$, income group (I), age of head-of-household (A), and presence of kids (K). We label the resulting 432-category market segments the "HIAK" distribution. MetroScope's residential submodel uses Census tracts (which we label "residential zones" or Rzones) as the spatial unit of analysis. The model also treats non-residential (employment) location choice but this paper focuses only on the residential submodel for brevity.

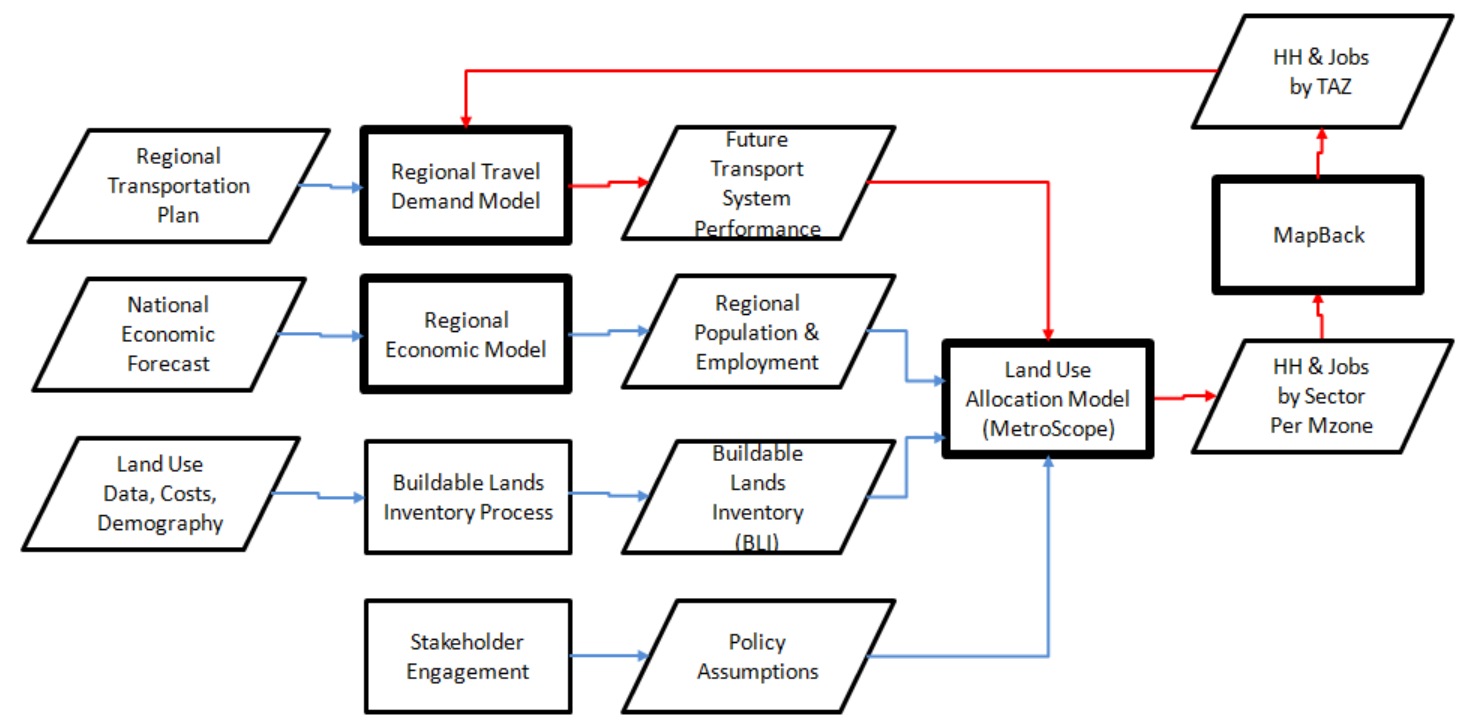

Figure 2: Metro land-use forecast toolkit

MetroScope was inspired by the work of Anas and Arnott (Anas, 1982; Anas \& Arnott 1991, 1997; Conder \& Lawton 2002). At its core MetroScope applies bid/rent theory as shown in Equations 1 and 2: hedonic "Bid" functions with zonal- and HIAK-specific inputs compute the amount households are willing to pay for a new housing unit while cost-based "Ask" functions with zone-specific inputs compute the amount developers will charge for new residential supply. As in real markets the model iterates through different household location choices until such time as Bids and Asks become equivalent and so reaches a market-clearing equilibrium solution.

MetroScope outputs new housing units by zone by type (single-family or multi-family) and ten- 
ure (own or rent). Staff apply Mapback to sub-allocate R-zone-level HIAK forecasts to Traffic Analysis Zones (TAZs) using base-year observed allocations as the seed. The TAZ-level product serves as an input to the Regional Travel Demand Model which feeds travel-time matrices back to MetroScope, completing the transport/land-use feedback loop (shown in red).

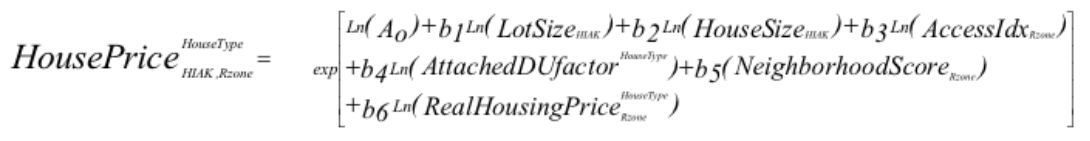

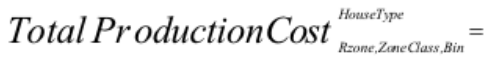

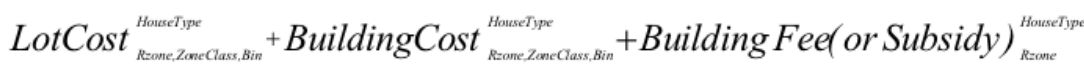

\subsection{The need for more decision-process and agent detail in MetroScope and other models}

Metro works closely with county and city staff to assemble the Buildable Lands Inventory (BLI), another key MetroScope input illustrated in Figure 2. The BLI encodes the amount of greenfield and re-developable land available for future construction. At this time, the BLI process applies one-time static treatments to estimate certain market interactions, specifically at what intensity (number of housing units) available already-built residential land would be re-developed should the market choose to do so. This means that in its current form MetroScope lacks endogenous treatment of supplier decision-making regarding whether and how many housing units to build and differentiation of new housing supply by project type. In response to these circumstances we have completed phase one of a submodel designed to internalize in MetroScope a more-detailed representation of developer decision-making and the different types and scales of the resulting simulated developments, and are conceptualizing enhancements to the consumer household location hedonic equations shown above that would more-explicitly sensitize the model to the presence of public goods.

\subsection{A submodel for more-detailed simulation of housing supplier decision-making}

\subsubsection{Pro forma-based developer submodel}

To more accurately forecast redevelopment supply we intend-similarly to other regional planning agencies' thinking (Waddell, 2013; Simonson, 2017)— to estimate supplier choices of how many housing units to build via a pro forma paradigm inside the MetroScope model rather than statically during input preparation. The pro forma approach is a practical heuristic technique used by firms to inform property development choices and to estimate the "highest and best use" for a particular property. The approach can be illustrated by an actual example not far from Metro's offices. In that case, a developer redeveloped a lot with existing structures in which the new building included fewer floors and units than permitted by zoning. The developer anecdotally reported that the chosen size made the best sense given current market conditions. To analytically implement such thinking Metro's approach posits 44 different development "prototypes" twelve of which are residential multi-family rental, eight of which are residential owned, and the rest of which are non-residential commercial/industrial. Table 2 shows the twenty residential prototypes normalized to a 40,000-square foot lot size (in implementation the lot size will be determined by the characteristics of the input taxlots). 
Table 2: Metro "pro forma” residential supply prototypes

\begin{tabular}{|c|c|c|c|c|c|c|c|}
\hline & Tenure & Density & Unit Count & $\begin{array}{l}\text { Ave Unit } \\
\text { Size }\end{array}$ & $\begin{array}{c}\text { Building } \\
\text { Square } \\
\text { Feet }\end{array}$ & FAR & $\begin{array}{c}\text { Parking } \\
\text { Ratio/Unit }\end{array}$ \\
\hline Rental high rise & Rental & 400 & 367 & 725 & 313,029 & 7.83 & 1.00 \\
\hline Rental Mid Rise w/ Garage & Rental & 225 & 206 & 750 & 181,765 & 4.54 & 1.00 \\
\hline Rental Type V w/podium & Rental & 170 & 156 & 750 & 134,483 & 3.36 & 1.25 \\
\hline Rental high rise-CC & Rental & 400 & 367 & 725 & 313,029 & 7.83 & 0.25 \\
\hline $\begin{array}{l}\text { Rental Mid Rise w/ Garage - } \\
\text { CC }\end{array}$ & Rental & 225 & 206 & 750 & 181,765 & 4.54 & 0.25 \\
\hline Rental Type V w/podium - CC & Rental & 170 & 156 & 750 & 134,483 & 3.36 & 0.25 \\
\hline Rental high rise-LP & Rental & 400 & 367 & 725 & 313,029 & 7.83 & 0.25 \\
\hline Rental Mid Rise w/ Garage - LP & Rental & 225 & 206 & 750 & 181,765 & 4.54 & 0.50 \\
\hline Rental Type V w/podium - LP & Rental & 170 & 156 & 750 & 137,647 & 3.44 & 0.50 \\
\hline $\begin{array}{l}\text { Rental 3-story wood zero } \\
\text { parked }\end{array}$ & Rental & 130 & 119 & 750 & 105,000 & 2.63 & 1.50 \\
\hline Rental 3-story wood w/surf & Rental & 35 & 32 & 750 & 24,000 & 0.60 & 1.50 \\
\hline $\begin{array}{c}\text { Rental 3-story wood } \\
\text { townhome }\end{array}$ & Rental & 20 & 18 & 1,000 & 18,000 & 0.45 & 1.50 \\
\hline Condo residential high rise & Own & 400 & 367 & 775 & 342,681 & 8.57 & 1.3 \\
\hline Condo Mid Rise w/ Garage & Own & 225 & 206 & 775 & 192,349 & 4.81 & 1.3 \\
\hline Condo Type V w/podium & Own & 170 & 156 & 775 & 142,235 & 3.56 & 1.5 \\
\hline Condo 3-story wood w/surf & Own & 35 & 32 & 800 & 25,600 & 0.64 & 2.0 \\
\hline $\begin{array}{c}\text { For-Sale 3-story wood } \\
\text { townhome }\end{array}$ & Own & 20 & 18 & 1,250 & 22,500 & 0.56 & 2.0 \\
\hline For-Sale Duplexes & Own & 18 & 16 & 1,250 & 20,000 & 0.50 & 2.0 \\
\hline Skinny Homes & Own & 18 & 16 & 1,500 & 24,000 & 0.60 & 2.0 \\
\hline Single Family & Own & 9 & 8 & 1,750 & 14,000 & 0.35 & 2.0 \\
\hline
\end{tabular}

Not shown for brevity are the costs of construction, maintenance, etc. Using such costs and other details a new submodel labeled the "Developer Supply Processor" (DSP) will allow MetroScope, for a given market price, to estimate the highest and best use for each developable and re-developable taxlot. The DSP will then output the number of residential units that a developer would likely produce. As of this writing our team has produced a standalone DSP implementation which Metro staff have tested in a static application to a test BLI dataset.

The team estimated DSP parameters using various data sets covering parts of the span of years 1990 to 2016 amalgamated from several sources: Metro's Regional Land Information System (RLIS) taxlots (parcels) layer, purchased third-party data on market rents throughout the region, and purchased Regional Multiple Listing Service (RMLS) data. Metro produces the RLIS taxlots layer by aggregating, cleaning, and standardizing county assessor data. The key conceptual goals of estimation dataset production were to incorporate achievable consumer sale prices and rents, market-rate property values, and a clear delineation of land use change (especially redevelopment) for all taxlots.

The tests processed tax lots for one analysis year for the entire region (roughly half a million lots) in about an hour. Since we usually apply the model in five-year increments across a twenty-to thirty-year horizon this will add about five hours to the current four-hour runtime. This evolution of MetroScope was endorsed recently by an expert peer review panel convened to help validate the DSP methods. The panel strongly recommended modernizing the housing production methodology in the land use model so that achievable market prices directly inform capacity estimation. 


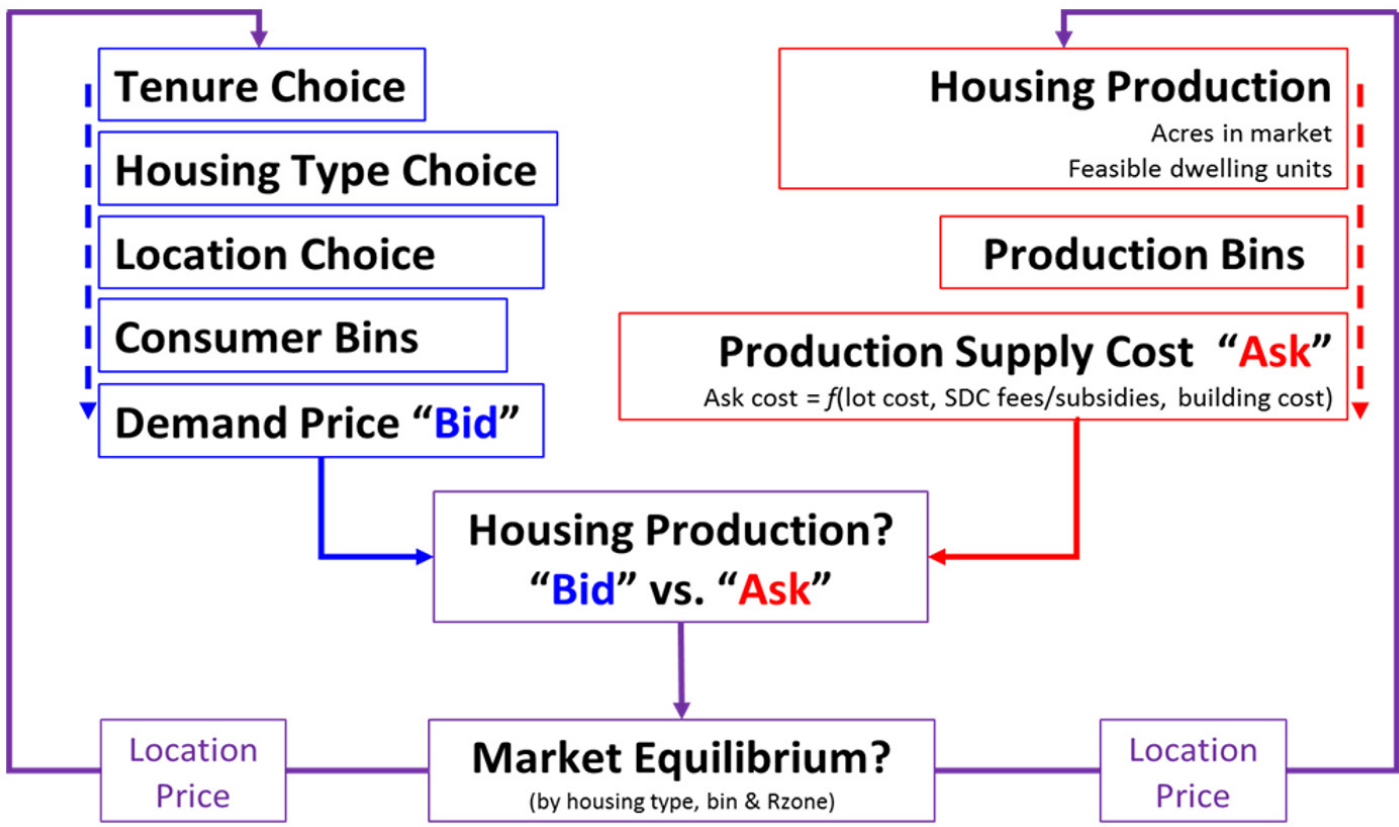

Figure 3: Current MetroScope residential submodel flow

As shown in the left side of Figure 3: Current MetroScope residential submodel flow the model currently steps through a sequence of hierarchical discrete choice utility functions which estimate consumer residential location choice tenure (own or rent), type (single-family or multi-family), and location choice (Rzone). MetroScope estimates housing supply (the right side of Figure 3) based on a heuristic approach deriving developable capacity based on a set of defined rules. The "Housing Production" step estimates development capacity (denoted in Equation 3 as "AcresAvailable") for each forecast year as a function of regulations such as zoning and environmental restrictions, or via asserted inputs for redevelopment and infill. In particular, redevelopment and infill supply is not currently responsive to iterative price signals or other endogenous terms available in the model. The term "FractionInMarket" is the current mechanism representing the developers' ability to produce housing. This term now enters the model as an asserted scalar input in the first analysis year although in subsequent years it is adjusted somewhat using the model's endogenous price signals. Since the "AvailableAcres" term is also an exogenous input from the BLI the current model's price estimation depends heavily upon exogenous factors. Staff and peer review panelists concur that internalizing developer behavior is theoretically attractive.

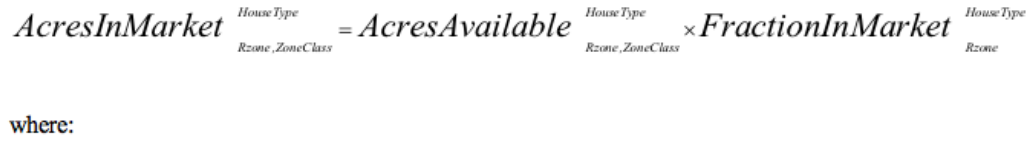


where: AcresAvailable in an exogenous input from the Buildable Lands Inventory (BLI)

where: FractionInMarket is a scalar fraction of the zonal land supply develop-able in each analysis year

where: LocPrice is an endogenous price term specific to each zone, representing to consumers their housing cost and to developers the sale price they would receive for producing a new dwelling unit

where: AcresInMarket is the Housing Production steps' output (the model keeps track of available land in acres)

The DSP submodel will replace the current "Housing Production" step illustrated in Figure 3. The DSP will take the endogenously estimated housing price as a key input for determining the "highest and best use" (H\&BU) of a taxlot and the supplier decision to (re-)develop or not. This re-formulation of MetroScope's supply-side will internalize developer decision-making directly in the model's iteration of supply/demand interactions. On the supply-side the model will thus more internally adjust to different levels of demand.

The DSP conceptual framework appears in Figure 4. The DSP takes tax lot characteristics (e.g., land area, zoned capacity) and the housing unit price from a previous model iteration as inputs, screens out prototypes ineligible for the zoning type, and predicts the prototypes (see Table 2) most profitable to construct as a probability (the "predicted yield") of the number of units that developers would produce at the given price point.

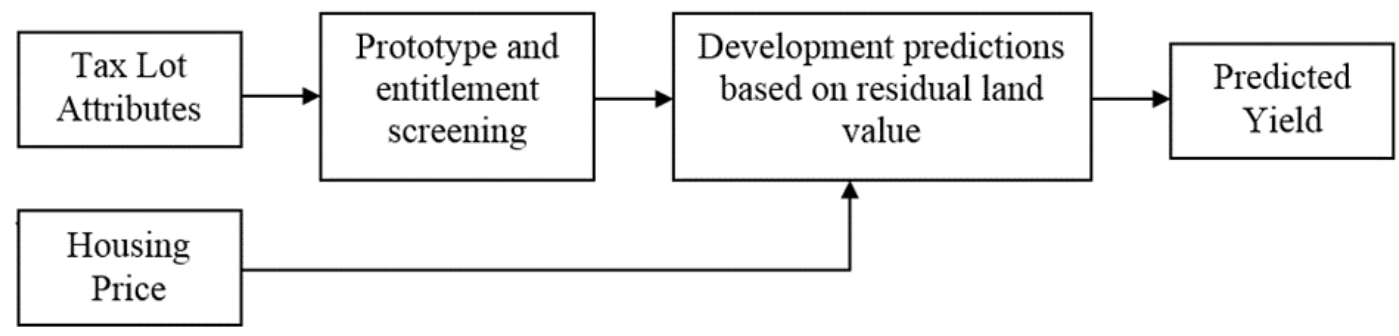

Figure 4: Conceptual model flow for the DSP for one MetroScope iteration

Figure 5 illustrates the DSP "development prediction" step, which applies three sub-iterations for calculating a primary, secondary, and tertiary $\mathrm{H} \& \mathrm{BU}$. The three $\mathrm{H} \& \mathrm{BU}$ steps are intended to avoid the case of unrealistically building the same prototype repeatedly. The DSP produces zero to three $\mathrm{H} \& \mathrm{BU}$ per taxlot with the sum of the predicted yields for all H\&BUs being the total predicted yield for that lot. 


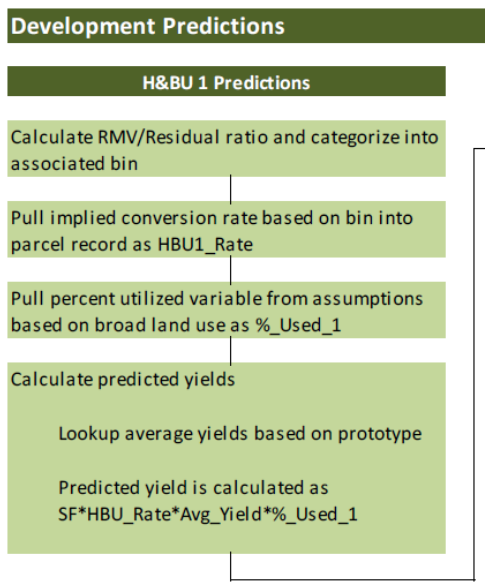

H\&BU 2 Predictions
Calculate RMV/Residual ratio and categorize into
associated bin
Pull implied conversion rate based on bin into
parcel record as HBU2_Rate
Pull percent utilized variable from assumptions
based on broad land use as \%_Used_2
Calculate predicted yields
Lookup average yields based on prototype
Predicted yield is calculated as
SF*HBU_Rate*Avg_Yield*(1-
\%_Used_1)*\%_Used_2

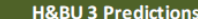

Calculate RMV/Residual ratio and categorize into associated bin

Pull implied conversion rate based on bin into parcel record as HBU3_Rate

Pull percent utilized variable from assumptions based on broad land use as \%_Used_3

Calculate predicted yields

Lookup average yields based on prototype

Predicted yield is calculated as

SF*HBU_Rate*Avg_Yield*(1-\%_Used_1)*(1-

\%_Used_2)*\%_Used_3

Figure 5: DSP development prediction workflow

Instead of static "acres available," the DSP will endogenously set supply. "AcresInMarket" in the MetroScope model will, after DSP incorporation, be computed with the new term "PredictedYield" in place of "AcresAvailable": in other words, equation 3 will become equation 4 . Note that we omit the details of dwelling-unit-to-acres conversion in this paper; the BLI accounting is all done in units of acres).

\section{AcresInMarket RouseType $_{\text {RzoneClass }}^{\text {Honene }}$}

$$
=\text { PredictedYield } \text { Rzone,ZoneClass }_{\text {Hone }} x \text { UnitsToAcres }_{\text {Rzone }}^{\text {HouseType }}
$$

\section{RENTAL APARTMENTS}

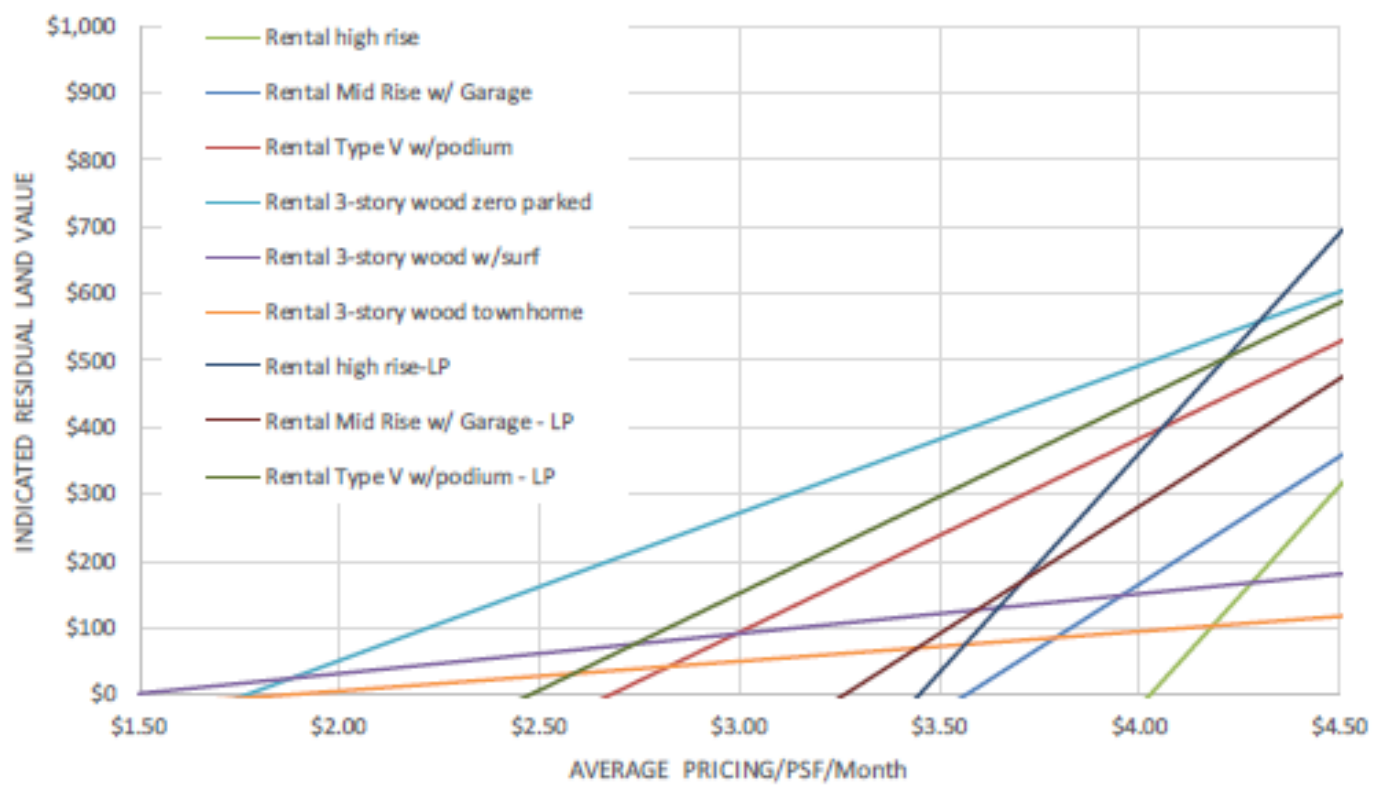

Figure 6: Highest and best use example 
Figure 6 illustrates how the DSP simulates calculation of a predicted yield representing capacity that is market-ready using the pro forma logic. It shows the production curves for a hypothetical taxlot zoned to permit high-capacity multi-family housing. Note that if achievable rents are in the range of about $\$ 2.00 /$ sq. $\mathrm{ft}$. to over $\$ 4.00 / \mathrm{sq}$. ft. the market-feasible development would be a 3-story wood frame apartment building with a surface parking lot. If achievable rents rise to $\$ 4.50 /$ sq. ft., however, the pro forma "pencils out" the highest and best use to be a high-rise apartment building with limited on-site parking. Re-development costs enter through the price inputs.

In addition to the predicted yield the DSP can preserve the chosen prototypes as an output, allowing us to display the most likely development types forecast in various geographies around the region. This additional detail will, we intend, not only improve model validity but provide more compelling means of communicating forecast findings to stakeholders and decision-makers.

\section{Potential future research-more-detailed residential consumer decision- making}

The policy questions that Metro planners and councilors are currently asking call for additional model details across several dimensions of our representation of demand for housing: household attributes, neighborhood attributes, and heterogeneity in household preferences for neighborhood attributes. MetroScope, like many land use and transportation models, relies on basic household characteristics to drive behavior, primarily the aforementioned HIAK segmentation variables. These dimensions have been chosen for their forecastability as much as for their predictive power. In the current model, residential neighborhoods differ by housing prices, accessibility (travel times to jobs), and a "neighborhood score" that tries to capture all other elements that make a house in one location more or less desirable than the identical house in a different location.

In reality, households with identical HIAK characteristics often make very different housing choices based on their lifestyle preferences. For example, one family might choose a small house in a dense neighborhood close to jobs while another chooses a large suburban house with a long commute. Our model needs to be more responsive to these variations in preferences.

The existing neighborhood score is designed to account for all the location attributes that are not explicitly included in the location choice model. Staff estimated the score as the residual from a hedonic equation that nets out the effects on housing prices of the variables that are included directly in the model equations, namely accessibility, house size and lot size. The score represents the value of a particular location after accounting for these basic attributes and implicitly includes housing quality, walkability, bike friendliness, school quality, and other observable and unobservable neighborhood characteristics that home buyers typically care about. MetroScope interacts neighborhood score with household income as shown in Equation 1.

Neighborhood score is an attractive way to reduce choices to a tractable set of options but it has shortcomings. First, hedonic analysis in general ignores the spatial sorting that takes place due to heterogeneous household preferences. Housing prices in a particular neighborhood reflect the value of that location to the people who have chosen to live there and cannot necessarily be generalized to all households in the region. Second, it is unclear how the neighborhood score should be adjusted in response to policy choices and investments made by Metro and our regional partners. We propose to unpack the neighborhood score into multiple neighborhood variables and to incorporate additional variation in household tastes for such variables as a step toward addressing these issues.

One way to characterize variation in preferences for housing is along a spectrum of relative demand for public goods and private consumption. Some households place a high value on sidewalks, bike lanes, parks and other shared assets while other households are more interested in purchasing a larger house 
with a larger, private yard but fewer neighborhood amenities. The variables of interest to Metro could be pulled out of the neighborhood score by creating a neighborhood index of public goods that can be explicitly included in the hedonic analysis. If we include variables for shared assets such as parks, biking and walking facilities, then the elements remaining in the residual (housing quality, school quality, etc.) might be more strongly correlated with the income dimension of the HIAK. To implement preference heterogeneity on the household side, we could introduce a public goods taste parameter as another dimension to the HIAK forecast. This sort of approach has been implemented in residential sorting models in the economics literature, where households choose among a number of jurisdictions with varying levels of public good provision and corresponding levels of taxation (Calabrese, Epple, Romer, \& Sieg, 2005; Sieg, Banzhaf, Smith, \& Walsh, 2004). In this framework, households are typically differentiated by their income and a taste parameter that reflects their valuation of a public good index. All households agree that more public good is better, but the taste parameter allows some households to place a low value on the public good relative to housing attributes while others place a high value on the public good.

This vertical differentiation of public goods across neighborhoods is obviously a simplification of household preferences. However, it may be a tractable first step toward introducing more preference variation to Metro's land use modeling. Household preferences for the public goods of interest to Metro policymakers, including parks and improved facilities for walking and biking, are likely to be strongly correlated. Wrapping them into a single index would be a reasonable approach in that case and would increase the integration between the land use and transport models. Road improvements, another public good of interest to Metro, should already be captured by travel accessibility variables in the travel demand model.

This discussion has abstracted from some practical issues with this approach. Estimating and forecasting the additional details of a household taste parameter that is not strongly tied to any of the existing HIAK dimensions will be challenging. Both tastes and neighborhood characteristics will likely change over time yet forecasting each is challenging. We may thus want to take a scenario planning approach to this issue and consider the market implications of various future distributions for the taste parameters. The existing spatial scale and boundary locations of the model zones present another challenge. Census tracts do not usually define neighborhoods in a meaningful way to households and may not be a good geography for the measurement and aggregation of existing neighborhood amenities or planned future investments. However, Metro has administered one instance of a consumer housing preferences survey and intends to repeat it. Doing so may offer an opportunity to better define the taste parameter.

On the supplier side the team has theorized about whether it would be appropriate to differentiate amongst different types of developers. It is conceivable, for example, that a consortium of nongovernmental organizations (NGOs) and public agencies working on affordable housing issues might have a different calculus for return on investment. Anecdotal evidence from real estate firms and Metro's own transit-oriented development staff suggests that property owner decision-making also plays a role, perhaps less on how a property placed in the market would redevelop but rather when a property might come on the market. At the present time, the DSP assumes that developers are homogeneous and that market-ready properties will readily be put into production if demand exists. However, Metro staff and the consultant members of the DSP team have formed contacts with developers and realtors and may attempt to explore these dimensions in a focus group setting.

\section{Conclusions}

Our Developer Supply Processor phase one tests and our conceptual look-ahead to enhanced consumer choice elements of MetroScope suggest that aggregate, spatial-equilibrium land use allocation models 
can meaningfully simulate more-detailed decision processes in tractable and useful ways. Our work gives aggregate model users means of applying pro forma techniques similar to those already in use in agent-based approaches. This ability may be of practical significance to other practitioners who, like ourselves, face the strategic choice of whether to answer more sophisticated policy questions via upgrading a legacy aggregate model or whether to switch to one of the agent-based micro-simulation frameworks. The strategic question is not trivial both from the perspective of cost to agencies and from a theoretical viewpoint.

It is illuminating to return to the policy questions framed in our introduction: what policies promote or hinder redevelopment? Metro's DSP tests suggest that, as one might expect, the DSP seems sensitive to policies that would affect publically-imposed development fees. Such fees can be noticeable-more than $\$ 2,500$ per unit for transportation-related fees alone within the Portland city limits (City of Portland, 2018). Further tests will be made to assess the model's sensitivity to more-nuanced policy factors.

From a cost perspective, the ability to incrementally upgrade aggregate model frameworks is attractive since it can be done without massive infusions of funds. While agencies have demonstrated in the travel forecasting field (Clarke, Davidson, \& Thomas, 2008) that a model evolutionary path can proceed from aggregate to hybrid aggregate/agent-based to fully agent-based paradigms, agencies may face constraints that make it attractive to be able to minimally enhance an aggregate model for added years of viability.

From a theoretical viewpoint, the literature contains a lively discussion about the efficacy of spatial equilibrium models that seek a market-clearing solution via aggregate market segments versus agentbased techniques that reach computational closure through other means. We offer no opinions on that debate in this paper but do think that the incremental MetroScope enhancements described herein can be valuable to practitioners who, like ourselves, are attempting to "modernize" an existing aggregate model to be relevant for future analytic needs. 


\section{References}

Anas, A. (1982). Residential location markets and urban transportation: Economic theory, econometrics and policy analysis with discrete choice models. New York: Academic Press.

Anas, A. (2013). A summary of the applications to date of RELU-TRAN, a microeconomic urban computable general equilibrium model. In Environment and Planning B: Planning and Design, 40, 959-970.

Anas, A., \& Arnott, R. J. (1991). Dynamic housing market equilibrium with taste heterogeneity, idiosyncratic perfect foresight and stock conversions. Housing Economics, 1(1), 2- 32.

Anas, A., \& Arnott, R. J. (1997). Taxes and allowances in a dynamic equilibrium model of urban housing market with a size-quality hierarchy. Regional Science and Urban Economics, 27, 547-580.

Anas, A., \& Liu, Y. (2007). A regional economy, land-use, and transportation model (relu-tran): Formulation, algorithm design, and testing. Regional Science, 47(3), 415-455.

Calabrese, S., Epple, D., Romer, T., \& Sieg, H. (2005). Local public good provision: Voting, peer effects, and mobility. Journal of Public Economics, 90, 959-981.

City of Portland. (2018). Systems development charges. Retrieved from https://www.portlandoregon. gov/bds/34186

Clarke, P., Davidson, P., \& Thomas, A. (2008, October). Migrating four-step models to an activity based modelling framework in practice. Paper presented at the European Transport Conference, Leiden, Netherlands.

Conder, S., \& Lawton, K. Alternative futures for integrated transportation and land use models contrasted with trend-Delphi models: Portland, Oregon, metro results. Transportation Research Board, 1805, 99-107.

Felsenstein, D., Axhausen, K. W., \& Waddell, P. (2010). Land use-transportation modeling with UrbanSim: Experiences and progress, introduction to the special issue. Journal of Transport and Land Use, 3(2), 1-3.

Mokhtarian, P. L., \& van Herick, D. (2016). Quantifying residential self-selection effects: A review of methods and findings from applications of propensity score and sample selection approaches. Journal of Transport and Land Use, 9(1), 7-26.

Oregon Metro. (2014). Urban growth report, appendix 5: Residential development trends. Retrieved from http://www.oregonmetro.gov/urban-growth-report

Puget Sound Regional Council. (2015). 2012 Land use forecast. Retrieved from https://www.psrc.org

Pendyala, R., Gardner, B., Hickman, M., Karthik, K., Noh, H., Waddell, P., Wang, L., You, D., \& Yi-Chang, C. (2014). Integrated land-use-transport model system with dynamic time dependent activity-travel microsimulation. Transportation Research Record, 2303, 19-27.

Phelps-Goodman, E. (2016, July 18). Seattle demolitions bring displacement, not enough density. Crosscut. Retrieved from https://crosscut.com/2016/07/seattle-demolitionsbring-displacementnot-enough-density

Sieg, H., Banzhaf, H. S., Smith, V. K., \& Walsh, R. (2004). Estimating the general equilibrium benefits of large changes in spatially delineated public goods. International Economic Review, 45(4), 1047-1077.

Simonson, M. (2017). Personal communication to the authors.

State of Oregon. Oregon revised statutes. Retrieved from https://www.oregonlaws.org/ors/197.296.

Waddell, P. (2013). Draft technical documentation: San Francisco Bay Area UrbanSim application. Technical report. Berkeley, CA: Institute of Urban and Regional Development, University of California, Berkeley. 
Wang, L. (2013). A disaggregated real estate demand model with price formation for integrated land use and transportation modeling. Paper presented at the Transportation Research Board Annual Meeting, Washington, D.C.

Wegener, M. (2012). Applied models of urban land use, transport. In, Network infrastructure and the urban environment: Advances in spatial systems modelling. Berlin: Springer Science \& Business Media.

Zhang, W., \& Kockelman, K. M. (2016). A dynamic land-use model with location externalities and zoning regulations. In Innovations in urban and regional systems: Contributions from GIS\& T, spatial analysis and location modeling. New York: Springer. 